\title{
Tweedetaalteorie vir die eerstetaalonderwyser
}

Ludolph Botha

In hierdie artikel word die eerstetaalonderwyser se aandag op tweedetaalteorie gevestig. Krashen se tweedetaalteorie word uitgesonder en die implikasies van sy werk vir eerstetaalonderwysersword ondersoek. Die oordrewe beklemtoning van vormen struktuur in moedertaalklasse (oor die taal praat/lees/skryf) word vanuit die gesigspunt van Krashen se taalverwerwingsteorie beskou en die gevolgtrekking word gemaak dat daar veel meer klem op gebruiksvaardigheid behoort te val (in die taal praat/lees/skryf).

In this article the first language teacher is made aware of second language teaching theory. Particularly Krashen's second language theory is referred to and implications of his work for mother tongue teachers are discussed. The over-emphasis on form and structure in first language classes (talking/reading/writing about the language) is looked at in terms of Krashen's theory and it is concluded that the emphasis in first language classes should be far more on the functional use of the language (talking/reading/writing in the language).

Die spesifieke doel van hierdie artikel is om die eerstetaalonderwyser bewus te maak van die werk wat op die terrein van die onderrig van' $n$ ander taal as die moedertaal gedoen word ( $T_{1}$ word gebruik om eerste- of moedertaal aan te dui): Verder wil die artikel die $T_{1}$ onderwyser se aandag spesifiek op een van die tweedetaalteorieë vestig en veral op die implikasies daarvan vir die $\mathrm{T}_{1}$-onderwyser.

Die afgelope dekades was daar baie woelinge op die gebied van tweede- en vreemdetaalonderrig ( $T_{2}$ word gebruik om ' $n$ ander taal as die moedertaal aan te dui). Dit kan uitsluitlik aan 'n dringende behoefte aan beter kommunikatiewe vermoe in ander tale as die moedertaal toegeskryf word. Die groter behoefte aan taal vaardigheid het waarskynlik ontstaan as gevolg van ' $n$ verskeidenheid faktore, waarvan die volgende uitgesonder kan word:

* die feit dat die mens baie meer mobiel is en met behulp van moderne vervoermiddele binne ' $n$ kort tydsbestek in 'n ander land kan wees waar 'n vreemde taal gepraat word

* die feit dat moderne kommunikasiesisteme skakeling met enigiemand op feitlik enige plek op aarde moontlik maak

* die feit dat internasionale handel en kennisuitruiling kontak met ' $n$ groot verskeidenheid persone, en gevolglik tale, noodsaak.

Die groter behoefte aan kommunikatiewe bevoegdheid in ander tale het noodwendig gelei tot navorsing, ontwikkelinge en vernuwing op die gebied van $T_{2}$-onderrigmetodiek. In hierdie artikel word gepostuleer dat van die ontwikkelinge op die gebied van $T_{2}$-teorie 
moedertaalonderrig (met spesifieke verwysing na Afrikaans) kan verryk en moontlik selfs kan verbeter.

\section{'n Teoretiese raamwerk vir Eerstetaal-onderrig}

Dit is van die allergrootste belang dat die $T_{1}$-onderwyser binne ' $n$ teoretiese raamwerk moet werk as hy/sy die moedertaal onderrig. Hierdie teoretiese raamwerk sal onder andere die volgende kan insluit:

1 Doelstellings wat natuurlik nie die sillabusdoelstellings sal uitsluit nie. Dit is belangrik dat ' $n$ onderwyser sy/haar eie doelstellings met ' $n$ besondere klas formuleer (verkieslik op skrif). Dit is noodsaaklik om te weet waarheen ' $n$ onderwyser met ' $n$ klas op pad is en wat hy/sy wil hê hulle moet bereik.

2 Tegnieke en metodes wat in die klas aangewend gaan word. Dit sluit hulpmiddels in en is eintlik die "resep" wat gebruik gaan word om die leerstof aan die leerlinge te onderrig. Dit is die hoe waarna dikwels in onderwysgeledere verwys word.

3 Die taal wat in die klas gebruik gaan word. Dit sluit handboeke, uitdeelstukke, leesboeke, ens. in. Dit is die wat waarna dikwels verwys word.

4 Laastens - iets wat nie spesifiek vakgerig is nie, maar waaraan elke onderwyser aandag behoort te skenk: dit is die feit dat die hele (totale) kind die onderwyser se verantwoordelikheid is en dat die sterk invloed van die gesagsfiguur (die onderwyser) op die kind se psige besef moet word. Die leerstof is dan ook net ' $n$ middel tot die hoër doel om die kind psigies, geestelik, verstandelik en selfs liggaamlik so harmonieus (kongruent) as moontlik te laat ontwikkel en grootword.

\section{Tradisionele $T_{1}$-onderrig}

Die $T_{1}$ word dikwels op 'n uiters gefragmenteerde wyse onderrig. Daarmee word bedoel dat mondelinge kommunikasie, skriftelike stelwerk (kommunikasie), lees (letterkunde inbegrepe), begripstoetsing en taalstudie geïsoleerd (gewoonlik afsonderlike lesure) onderrig word asof dit los, aparte komponente is wat niks gemeen het nie. In sulke gefragmenteerde programme is die leerstof dikwels so uiteenlopend van aard dat die leerlinge nooit ' $n$ geheelbeeld kan vorm nie, of ' $n$ aspek van die taal op geïntegreerde wyse werklik bevredigend kan internaliseer nie.

Daar word baie oor die taalonderdele gesels, maar die taal as funksionele eenheid kom min, indien ooit, tot sy reg. Die taal word as ' $n$ objek aan die kind voorgehou wat dan as sodanig bestudeer word met toetsing agterna wat net op uiterlike, formele kennis klem lê. Die $\mathrm{T}_{1}$-leerkragte onderskei nie altyd tussen 'n studie van die struktuur ("grammatika" in die tradisionele sin) van die taal en taalvaardigheid nie. Daar word ook dikwels aanvaar dat 'n studie van die struktuur noodwendig tot beter taalvaardigheid sal lei en daarom word selfs die jong kind gedwing om op 'n meta-vlak met die taal om te gaan terwyl hy moeite ondervind om sulke abstraksies volkome te begryp. Romaine (1984:206) merk in hierdie verband op:

“... children have not developed a metalinguistic awareness of some aspects of language; this may pose problems for children in trying to make sense out of the way in which teachers talk about language." 
Die kind word gevolglik met abstraksies oor die taal besig gehou terwyl hy 'n dringende behoefte aan kommunikatiewe vaardigheid het wat hom gebruiksvaardiger sal maak sodat die taal as funksionele kommunikasiemiddel en kunsvorm, ook in die kind se hand (mond, oog en oor) kuns sal word.

Die oordrewe beklemtoning van evaluering (toetsing en eksaminering) dra ook veel tot die kwaad by. Die onderwysers is geneig om hul onderrig net op die eksaminering te rig, i.p.v. om die eksaminering na die onderrig te skik. Die klem op evaluering werk gevolglik die fragmentering van die taalkomponente en ' $n$ formele studie van die struktuur van die taal in die hand, want so ' $n$ werkwyse is baie makliker toetsbaar as 'n geïntegreerde en heel taal wat funksioneel ingespan word. Handboeke word ook só geskryf dat die komponente nog verdergeïsoleer word, en dit laat die fragmentasie verder toeneem en maak dit nog makliker om die fokus geheel en al op die toetsing en eksaminering te plaas. Meer en meer formele boekekennis van die taal word nagejaag met al minder oefening om die taal werklik effektief te kan gebruik.

Indien evaluering oorbeklemtoon word, val die klem voortdurend op die eindproduk terwyl die proses verwaarloos word. Aangesien die kind nog tot in laat adolessensie (en selfs nog daarna) taal verwerf (nuwe woordeskat, nuwe stelwyses, registers en nuanses), is die proses van die allergrootste belang. Met verwerwing word dus die voortdurende uitbouing van die gebruiksvaardigheid bedoel. Romaine (1984:4) stel dit soos volg:

"It is evident that communicative competence continues to develop well intoadulthood as one learns how to do new things with language."

In die alledaagse lewe is dit vir 'n kind uiters belangrik om hom te kan uitdruk in sy moedertaal, om te kan begryp wat sy maats sê, om hardop te dink in die $T_{1}$, om die diepste behoeftes en gevoelens te kan verwoord, ens. Die $T_{1}$ word dus benodig vir ' $n$ proses van selfuitdrukking, van begrypende sosialisering en selfkommunikasie - met ander woorde, gebruiksvaardigheid. In die tradisionele klaskamer word die fokus op 'n studie van die struktuur gerig wat vooraf deur 'n sillabusopsteller geïdentifiseer en dikwels ook gefragmenteer is; daarna word die leerlinge getoets om te sien hoe goed hulle die materiaal geleer het, of hoe goed hulle daaroor kan praat/skryf.

Die feit dat daar nie twee soortgelyke leerlinge in een klas sit wat op presies dieselfde wyse op onderrig reageer nie, word al duideliker uit die navorsing en ontwikkeling op die terrein van die leerpsigologie. Lewis (1987:59), wat onderrigbenaderings en die leerstyle van leerders wil versoen, verdeel byvoorbeeld alle leerders in vier groepe. Die kriteria vir die groepe is onder andere hemisferiese dominansie en denkstyle. Die volgende vier groepe word onderskei:

1 betrokke denkers (of leerders)

2 intellektuele denkers

3 implementerende denkers

4 vindingryke denkers.

Die probleem wat Lewis identifiseer, is dat die tradisionele skoolsisteem 'n baie klein persentasie van die leerlinge in 'n gegewe klas werklik doeltreffend aanspreek wat onderrigmetodes betref. Die volgende aanhaling illustreer die probleem:

"This is fine for 25 per cent of students (dit is nou die tradisionele aanbiedingswyses), but very unfortunate for the remaining 75 per cent whose mind styles make them uncomfortable with the way knowledge is presented and teaching structured. As a 
result, they become discouraged about many aspects of learning, frequently do poorly ... seldom enjoy praise from the teachers, and soon come to look on school studies as irrelevant. Their failures are not, however, due to their being less capable or, initially, less enthusiastic about their studies. But, because they are forced to use a thinking style which is alien to them, it is not long before they lose motivation and selfconfidence" (Lewis, 1987:65).

Net soos die denkstylvoorkeure vandag in die onderrigsituasie belangrik is, is daar onderlinge verskille tussen die leerlinge in die $\mathrm{T}_{1}$-klasse wat deur die leerkrag in berekening gebring behoort te word. In 'n moedertaalklas word daar dikwels onderrig asof ál die leerlinge in die klas dieselfde belangstelling in die struktuur van die taal het en asof almal dieselfde mate van skeppende vermoë in die taal het. ' $n$ Vraag wat alle moedertaalonderwysers behoort te stel, is: wat is my leerlinge se werklike moedertaalbehoeftes en op welke wyse kan ek soveel moontlik van daardie behoeftes die beste aanspreek? As die ware behoeftes van die leerlinge besef word, as die denkstylvoorkeure in ag geneem word en as die taal as 'n funksionele geheel gesien word, sal daar op 'n sinvoller wyse onderrig kan word.

Daar word nie gesuggereer dat die bestudering van die struktuur van die taal op sigself verkeerd is nie, maar wanneer daarna gekyk word, is die konteks waarbinne dit gebruik word, op watter stadium van taalontwikkeling daarmee begin word en die doelstellings van die onderrig daarvan van die uiterste belang. Die kind se werklike taalbehoeftes moet altyd voorrang geniet sodat die taal uiteindelik 'n nuttige instrument kan word wat hy funksioneel in sy leefwêreld kan gebruik.

\section{Stephen Krashen se taalverwerwingsteorie}

As daar na taalverwerwingsteorieë en onderrigbenaderings gekyk word op die terrein van $\mathrm{T}_{2}$-onderrig, kan kennis geneem word van die werk van Stephen Krashen. Alhoewel sy teorie deur sommige navorsers gekritiseer word (sien Carroll, 1986; Klein, 1986 en McLaughlin, 1987), beskou baie navorsers sy werk as 'n belangrike bydrae op die terrein van $T_{2}$-verwerwing (sien Krahnke, 1985; Stevick, 1986 en Vanpatten, 1987). 'n Ander rede waarom kennis geneem behoort te word, is die volgende: die $T_{1}$-leerling kom met sy/haar persoonlike idiolek na die klaskamer waar hy/sy blootgestel word aan die standaard vorm van die taal (en natuurlik ook die geskrewe vorm) wat twee nuwe taalsisteme behels wat hy moet bemeester. Romaine (1984:167) stel dit soos volg:

"In transition from home to school the relationship between language and context is one aspect of the child's experience which changes quite dramatically."

"Classroom talk is largely teacher-initiated, and the contexts in which learning is designed to take place are often unfamiliar to the child and are abstract."

Daardie blootstelling aan klaskamertaal en die geskrewe vorm van die taal gee aanleiding tot 'n verwerwingsproses wat in wese nie verskil van die verwerwing van 'n $T_{2}$ nie. Dus, al is Krashen se werk op $\mathrm{T}_{2}$-onderrig gemik, is daar veel te leer daaruit - ook vir die moedertaalonderwyser.

Krashen (1982:17) het byvoorbeeld by geleentheid gesê die sentrale hipotese van sy teorie is dat taalverwerwing slegs op een manier plaasvind, nl. om boodskappe te begryp. Daarmee sê hy dat kinders taal verwerf (hulle moedertaal) deur op die inhoud van die 
boodskap te konsentreer. Hulle fokus nie op hoe dit gesê word nie. Romaine (1984:1) laat die klem op gebruik val wanneer sy sê:

"Children acquire language by using it."

Volgens Krashen (1982:10) is die $\mathbf{T}_{\mathbf{2}}$-verwerwingsproses soortgelyk aan die $\mathbf{T}_{\mathbf{1}}$ verwerwingsproses. Dit is 'n onbewustelike, implisiete proses, en formele onderrig van die taal (met die klem op die struktuur) dra aanvanklik niks by tot daardie verwerwingsproses nie; inteendeel, daar word selfs beweer dat ouers (en selfs ook onderwysers) wat gedurig kinders se taal korrigeer, skade berokken aan die kind se taalverwerwing.

Teenoor verwerwing stel Krashen $(1981: 2 ; 1982: 10,89)$ taalleer. Leer beskou hy as die inwin van formele kennis oor die taal, bewuste kennis wat eksplisiet is, wat formeel onderrig kan word en wat vergelykbaar is met die onderrig oor die struktuur van die taal soos dit dikwels in 'n tradisionele $\mathrm{T}_{1}$-klaskamer plaasvind.

Die jong kind verwerf vroeg reeds groot volumes van sy moedertaal. Alhoewel daar aanvaar word dat die normale jongmens sy moedertaal grootliks teen adolessensie verwerf het, hou die verwerwingsproses (in die sin van die uitbouing van kommunikatiewe vaardigheid) nooit werklik op nie (Romain, 1984:4). Die kind is nog relatief jonk wanneer hy op skool met formele taalleer kennis maak en dan wil dit voorkom of die onderwysers té vroeg en té veel klem op taalleer lê, terwyl die kind nog baie taal het wat hy moet bemeester en funksioneel leer gebruik voordat hy formeel daaroor kan gesels/redeneer. Met ander woorde, moedertaalonderwysers, veral in die laerskool, behoort kommunikatiewe vaardigheid voor formele studie van die struktuur te stel en hulle behoort baie meer geleenthede aan hulle leerlinge te bied om taal te bemeester deur baie gebruiksgeleenthede te voorsien. Hierdie taalverwerwings- en taalleerbeginsel noem Krashen sy verwerwing/leerhipotese.

Nog ' $n$ hipotese van Krashen (Krashen en Terrell, 1983:28, 29, 33-35) is die natuurlikevolgorde-van-verwerwing-hipotese. Hiervolgens verwerf ' $n T_{2}$-leerder die klankpatrone, leksikale items en grammatikastrukture in 'n voorspelbare volgorde. Wat belangrik is, is die feit dat die taal verwerf word en nie geleer word nie. Wanneer grammatika aanvanklik formeel geleer word, dra dit min (of selfs niks) by tot die natuurlike verwerwingsvolgorde. Dit kan selfs 'n steurende effek op die $\mathrm{T}_{2}$-leerder se verwerwingsvolgorde hê.

Moedertaalsprekers verwerf hulle moedertaal ook in " $n$ bepaalde volgorde (Krashen en Terrell, 1983:28). Die tempo waarteen die taal verwerf word, verskil egter van persoon tot persoon. Juis om hierdie rede is dit belangrik om ook aan moedertaalsprekers genoegsame geleenthede te bied om hulle moedertaal behoorlik te verwerf voordat na die grammatika of struktuur van die taal gekyk word. 'n Onderwyser kan bv. in 'n st.2-klas besluit om sekere aspekte van die lydende vorm te behandel, maar nie al die leerlinge in daardie klas mag gereed wees vir daardie aspekte van die lydende vorm nie. [Volgens Romaine (1984:56) is daar dikwels probleme en vertragings met die verwerwing van die passief/lydende vorm.] In hulle verwerwingsproses mag van die leerlinge daardie aspekte van die taal nog nie verwerf het nie en sal pogings om die leerlinge iets te laat leer wat nog nie verwerf is nie, tevergeefs wees. ' $n$ Leerder raak eers vatbaar vir die leer (studie van die vorm of struktuur) van taal wanneer daar genoegsaam verwerf is (of wanneer die kommunikatiewe vaardigheid genoegsaam ingeoefen is). Eers dan is die taalgebruiker in staat om oor die taal te gesels en die patroonmatighede te begryp en te bespreek. 
Die volgende hipotese van Krashen se teorie, is die monitor-hipotese en dit sluit nóu aan by die vorige hipotese (Krashen en Terrell, 1983:30). Die monitor is, volgens Krashen, die bewustelik-geleerde taalkennis wat ' $n$ spreker of skrywer doelbewus aanwend om sy taaluitinge te verfyn (of dan te monitor) sodat dit so korrek as moontlik is. Indien 'n taalgebruiker egter te veel op sy monitor staatmaak, kan dit vlotheid in die wiele ry (Krashen en Terrell, 1983: 30). Wat hier vir die moedertaalspreker van belang is, is die feit dat daar wel 'n plek vir en 'n behoefte aan taalkennis is - bewuste kennis van die struktuur en werking van die taal. Wat deeglik in ag geneem moet word, is dat die monitor nie te vroeg oorbeklemtoon moet word nie: dan word die volgorde weer eens versteur; dan word taalleer voor taalverwerwing ingestoot en word die kar voor die perde gespan. Die beginsel wat hier telkens na vore kom, is dat taalleer taalverwerwing moet opvolg. Indien die twee omgeruil word, sal die natuurlike verwerwingsproses versteur word en sal leerlinge belangstelling in hulle moedertaal verloor, minder gemotiveer wees; en uiteindelik sal hulle gebruiksvaardigheid in hulle $T_{1}$ daaronder ly. Die vraag moet gestel word: Is dit nie júis die probleem in vele $T_{1}-$ klaskamers nie?

Die volgende hipotese kan as een van die belangrikstes beskou word. Die invoerhipotese dui op die taal waaraan ' $n$ taalverwerwer blootgestel moet word om effektief die taal te verwerf (Krashen, 1982:21, 22,24; Krashen en Terrell, 1983:32-33; Krashen, 1985:1-99). Volgens hierdie hipotese verwerf ' $n$ kind slegs taal wat hy begryp, maar dan moet 'n mens besef dat die konteks ook help met die verstaanbaarheid van ' $n$ bepaalde hoeveelheid taal. Daarom glo Krashen dat die taalaanbod (die taalinvoer) ryk, gevarieerd en rofweg op die kind se vaardigheidsvlak gemik moet wees. Hy stel dit so: $i+1$ wat invoer plus een beteken. Dus, die taal waaraan ' $n$ kind blootgestel behoort te word, moet rofweg op sy vaardigheids-/begripsvlak gemik word, maar tog ook effens bokant sy vlak (die +1$)$. Uit die konteks lei die kind die betekenis van die +1 af en dit trek hom op - laat hom verwerf wat hy nog nie verwerf het nie.

Krashen (1983:34-35) vergelyk dit met visvang met 'n net. Die onderwyser gooi 'n net van taal uit, rofweg gemik op die klas se vaardigheidsvlak (die skool visse). Dit is nie presies-geselekteerde taalelemente (of taalstrukture) nie, maar altyd die hele taal wat binne 'n konteks gebruik word.

Die teendeel word ook met visvang vergelyk: indien 'n onderwyser die fokus op taalelemente (-strukture) laat val wat lineêr en dikwels geïsoleerd aangebied word, herinner dit aan ' $n$ man wat met 'n enkellyn visvang. Die hoogte (vlak) van sy hoek met die aas mag bokant die skool visse wees en daarom kan dit gebeur dat hy nie een vis vang nie. Anders gestel: nie een leerling in die klas mag gereed wees vir die spesifieke taalaspek waarop die onderwyser vir die dag besluit het nie - soos die genoemde voorbeeld van 'n st. 2-klas wat nie gereed is vir ' $n$ aspek van die lydende vorm nie. Die rofweg-gemikte net van taal sluit gewoonlik al die leerlinge in en daar is genoeg taalmateriaal en -verskeidenheid om aan almal se behoeftes te voldoen - ook wat addisionele verwerwing $(i+1)$ betref.

Hierdie hipotese van Krashen hou beslis implikasies vir die $\mathrm{T}_{1}$-onderwyser in wat té vroeg en té veel klem op struktuur lê. Ook in die $T_{1}$-klas behoort 'n ryk aanbod van rofweggemikte taal voorkeur te geniet. Eers as die leerlinge vér gevorder het met die verwerwing (of kommunikatiewe vaardigheid) van hulle $\mathrm{T}_{1}$, sal hulle die behoefte én die vermoë hê om oor die taalelemente te gesels. Krashen en Terrell (1983:19) sê ook baie pertinent dat hulle twyfel aan die waarde van kennis oor die struktuur van die taal wanneer dit by taalverwerwing 
kom. Soos by die monitor-hipotese aangetoon is, kan kennis oor die struktuur van die taal (die monitor) eers ' $n$ betekenisvolle rol speel nadat ' $n$ sekere aspek van die taal ten volle bemeester is.

Dit lyk dus of ' $\mathrm{n}$ ryk taalaanbod ook die norm vir $\mathrm{T}_{1}$-onderrig behoort te wees. Daardeur sal die $T_{1}$-leerkrag verseker dat sy/haar leerlinge 'n verskeidenheid van geskikte taal sal bemeester wat vir hulle binne hulle leefwêreld bruikbaar sal wees.

Krashen (1982:24) se volgende hipotese is die affektiewe-filtreerder-hipotese wat deur sommige toegepaste linguiste as sy belangrikste bydrae beskou word. Volgens hierdie hipotese kan sekere mense met sekere persoonlikhede, gesindhede en motiverings beter taal verwerf as ander. Daarby is sekere situasies beter geskik vir taalverwerwing as ander.

Die affektiewe filtreerder is emosionele weerstand wat ' $n$ rol by taalverwerwing speel. Die weerstand tree in werking by mense met 'n lae motiveringsvlak, 'n gebrek aan selfvertroue, 'n swak selfbeeld en wat angs ervaar. Uiteraard sal die laaste toestand, $\mathrm{nl}$. angstigheid by leerders, deur die leeromgewing bepaal word.

Die affektiewe filtreerder verhoed dat invoer (taalaanbod) deur die leerder geïnternaliseer word. Anders gestel, die taal waaraan die leerder blootgestel word, sal nie deur die leerder verwerf word as die filtreerder in werking is as gevolg van een van die genoemde redes nie.

"If the affective filter is 'up', no matter how beautifully the input is sequenced, no matter how meaningful and communicative the exercise is intended to be, little or no acquisition will take place" (Krashen, 1981:110).

In die $T_{1}$-klas sal dit ook baie belangrik wees dat die affektiewe filtreerder nie taalverwerwing blokkeer nie. Daarom moet die onderwyser rekening hou met die leerlinge wie se selfbeeld nie na wense is nie, situasies vermy waar leerlinge aan vrees (angs) blootgestel word en taalmateriaal kies wat intrinsieke motivering sal aanmoedig - die materiaal moet gevolglik baie interessant wees en kommunikatiewe deelname ontlok. In $\mathrm{T}_{1}$-klasse waar die taal voordurend en te vroeg as objek bestudeer word en daar uitsluitlik OOR die taal gesels/gelees/geskryf word, sal die affektiewe filtreerder beslis verdere bemeestering van die moedertaal (in daardie klasse) belemmer, veral by die leerlinge wat min belangstelling in daardie aspekte van die taal toon.

Die laaste hipotese van Krashen wat uitgesonder word, is die aanleghipotese (Krashen en Terrell, 1983:39-40). Hiervolgens beskik sekere mense oor'n aanleg vir taalleer. Sulke mense toon dus ' $n$ besondere belangstelling in die struktuur van die taal, die patroonmatighede en hoe alles inmekaarsteek. Krashen beweer dat so ' $n$ aanleg verband hou met taalleer en min te doene het met taalverwerwing. Iemand wat aanleg in die taalwetenskap toon, sal dit alleenlik toon nadat die persoon die taal grootliks bemeester het. Die gebruiksvaardigheid van iemand wat nie aanleg in taalleer toon nie, sal nie noodwendig swakker wees as iemand wat taalaanleg toon nie. ' $n$ Mens kan aanvaar dat die monitor van diegene wat taalleeraanleg het, beter ontwikkel sal wees as dié wat net goeie verwerwers is. Tog moet dit beklemtoon word dat goeie verwerwers nie noodwendig swakker taalgebruikers as diegene met taalleeraanleg is nie. ' $n$ Voorbeeld is die ou boere-oom wat ' $n$ uithaler storieverteller is. Hy het waarskynlik weinig (of geen) formele taalonderrig ontvang en weet waarskynlik niks van die struktuur van die taal nie. Tog gebruik hy die taal op 'n uiters vaardige wyse en dikwels is dit veel aangenamer (en verstaanbaarder) om na so iemand te luister as na 'n taalgeleerde.

Die volgende analogie kan ook gebruik word om die onderskeid tussen taalaanleg en 
goeie taalverwerwers aan te dui: iemand wat leer motor bestuur, hoef nie noodwendig presies te weet wat in die motor se masjien aangaan nie (goeie taalverwerwer). Daarteenoor is 'n goeie motorwerktuigkundige nie noodwendig 'n goeie bestuurder van 'n motor nie. Dikwels word die leerlinge se kennis van die masjinerie van die taal beklemtoon, terwyl die onderwysers se belangrikste plig is om toe te sien dat die leerlinge eers die taal doeltreffend kan gebruik (die motor doeltreffend kan bestuur).

Die $\mathrm{T}_{1}$-onderwyser moet dus bewus wees daarvan dat taalverwerwing 'n voortdurende proses is wat klem op die struktuur moet voorafgaan, maar dat daar wel 'n klein persentasie leerlinge sal wees wat taalleeraanleg sal toon en moontlik die toekomstige taalgeleerdes kan word. Vir hierdie leerlinge moet geleenthede geskep word om hulle aanleg te ontwikkel, maar die ander leerlinge in die klas moet nie opgesaal word met ' $n$ oordosis van taalleer net omdat daar 'n paar toekomstige linguiste onder hulle is nie.

\section{Slotsom}

In die geheel gesien, blyk dit dat dit veral die $\mathrm{T}_{1}$-leerkrag van jonger moedertaalleerlinge is wat kennis van Krashen se teorie behoort te neem, want hulle leerlinge het nog nie klaar hulle $T_{1}$ verwerf of ten volle bemeester nie. Selfs ouer moedertaalsprekers verwerf of bemeester voortdurend nuwe woordeskat, nuwe stelwyses, registers en nuanses. Indien die teorie (hipoteses) dus vir die jonger taalverwerwers geld, geld dit beslis ook vir ouer taalverwerwers.

Beheptheid met vorm of struktuur doen veel kwaad in moedertaalklaskamers en leerlinge, sowel as onderwysers, ly daaronder. Hierdie versmorende benadering om té gou en té veel OOR die taal te praat, kan en behoort te verander na 'n benadering waar eers IN die taal gepraat word. ' $n$ Benadering waar rekening gehou word met die teorie en ontwikkelinge op die gebied van $\mathrm{T}_{2}$-onderrig en ook " $\mathrm{n}$ benadering wat $\mathrm{T}_{1}$-onderrig vir die kind 'n ervaring kan maak waar hy leer om sy moedertaal as lewende kommunikasiemiddel te gebruik en te geniet.

\section{Bibliografie}

BLAIR, ROBERT W. (Ed.). 1982. Innovative approaches to language teaching. Massachusetts: Newbury House Publishers, Inc.

BLAIR, ROBERT W. 1983. Two paradigms of learning. INTUSNews, Vol. 7, No. 2,4249.

BLAIR, ROBERT W. 1985. Stories and story telling in first-level language learning : A re-evaluation. Per Linguam, Vol. 1, No. 2, 25-33.

BOTHA, H. L. 1983. Vordering op die gebied van tweedetaalonderrig ( $\mathrm{T}_{2}$-onderrig): Drie ander vakdidaktiese benaderings. Klasgids, Oktober 1983, 87-94.

BOTHA, H. L. 1985. Suggestopedagogiek in die klaskamer met verwysing na ooreenstemmende beginsels in ander vakdidaktiese benaderings. Tydskrif vir Taalonderrig , Vol. 19, No. 3, 63-70.

BOTHA, H. LUDOLPH. 1986. Sugggestopaedia for second language acquisition. Unpublished D. Ed. dissertation, University of Stellenbosch, Stellenbosch. 
BOTHA, H. LUDOLPH. 1987a. The role of error correction in communicative second language teaching. Per Linguam, Vol. 3, No. 2, 46-51.

BOTHA, H. LUDOLPH. 1987b. Suggestopaedia: Theory and application in teachers' colleges. The Journal of the National English Second Language Association for Teacher Training, No. 2, 6-17.

BOTHA, H. LUDOLPH. 1988. Suggestopedia in terms of Krashen's second language acquisition theory. Journal of the Society for Accelerative Learning and Teaching, Vol. 13, No. 4, 329-345.

CARROLL, JOHN B. 1986. Second language. In Robert J. Sternberg and Ronna F. Dillon (Editors), Cognition and instruction. Orlando: Academic Press, Inc.

HAND, JAMES D. 1984. Split-brain theory and recent results in brain research: Implications for the design of instruction. INTUS NEWS, Vol. 8, No. 2, 9-21.

KLEIN, WOLFGANG. 1986. Second language acquisition. Cambridge: Cambridge University Press.

KRAHNKE, KARL J. 1985. Review of the natural approach. Language acquisition in the classroom, by Stephen D. Krashen and Tracy D. Terrell. TESOL Quarterly, Vol. 19, No. 3, 591-603.

KRASHEN, STEPHEN D., Michael A. Long and Robin Scarcella. 1979. Age, rate and eventual attainment in second language acquisition. TESOL Quarterly, Vol. 13, No.4, 573582.

KRASHEN, STEPHEN D. 1981. Second language acquisition and second language learning. New York: Pergamon Press, Inc.

KRASHEN, STEPHEN D. 1982. Principles and practice in second language acquisition. New York: Pergamon Press, Inc.

KRASHEN, STEPHEN D. and Tracy D. Terrell. 1983. The natural approach. Language acquisition in the classroom. New York: Pergamon Press, Inc.

KRASHEN, STEPHEN D. 1985. The input hypothesis: Issues and implications. New York: Longman.

LEWIS, DAVID. 1987. Mind Skills. Giving your child a brighter future. Bristol: WBC Print Ltd.

LOZANOV, GEORGI. 1978. Suggestology and outlines of Suggestopedy. New York: Gordon and Breach.

MCLAUGHLIN, BARRY. 1987. Theories of second language learning. London: Edward Arnold Publishers.

ROMAINE, SUZANNE. 1984. The language of children and adolescents. The acquisition of communicative competence. London: Basil Blackwell.

STEVICK, EARL W. 1986. Images and options in the language classroom. Cambridge: Cambridge University Press.

VANPATTEN, BILL. 1987. On babies and bathwater: Input in foreign language learning. The Modern Language Journal, 71, ii, 156-164. 